\title{
Safety, effort and findings of gastric sleeve operation for morbidly obese patients
}

\author{
Wesam Amr MD; Ashraf Ismael MD; Morsi Mohamed MD, Yahia Zakaria MD
}

\author{
Departmrnt of General Surgery, Ain Shams University, Cairo, Egypt.
}

Background: Sleeve gastrectomy is a surgical technique to treat morbid obesity by both restrictive and probably hormonal action. Originally developed as a first stage to gastric bypass, it is more and more performed as a sole procedure. Therefore it is important to report results on weight loss and reduction in co-morbidity.

Patients and methods: Sixty morbidly obese patients (15 male, 45 female) were studied with a mean age $35 \pm 10.9$, mean BMI of $47.4 \pm 7.8 \mathrm{~kg} / \mathrm{m}^{2}$. All were evaluated and managed by sleeve gastrectomy from January 2009 to January 2012 in the General Surgery Department, Zagazig University Hospitals, 30 patients were associated with co-morbidity. Preoperative demographic data, operative data and postoperative follow up at $3 \mathrm{~ms}, 6 \mathrm{~ms}, 12 \mathrm{~ms}$ were collected.

Results: Laparoscopic sleeve gastrectomy (LSG) was done in 59 patients with conversion to open in one patient; major postoperative complication was bleeding (1pt.). The mean operative time of the procedure including anesthesia was $155 \pm 18.5 \mathrm{~min}$. The mean hospital

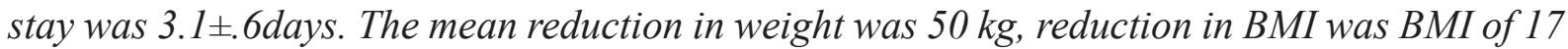
$\pm 4.9 \mathrm{~kg} / \mathrm{m}^{2}$ and reduction in $\% E W L$ was $48.7 \pm 15$. Complete resolution was $76.7 \%$ in 23 cases of co-morbidity patients.

Conclusion: Sleevegastrectomy can be performed safely with acceptable complication rates and good weight loss with good efficacy on the co-morbidity management.

Key words: Sleeve gastrectomy, morbid obesity, weight loss.

\section{Introduction:}

Bariatric surgery remains the only effective treatment for inducing and maintaining satisfactory weight loss and reducing weightrelated co-morbidities for the morbidly obese patient. ${ }^{1}$

Bariatric surgery includes a variety of procedures performed on people who are obese. Weight loss is achieved by reducing the size of the stomach with an implanted medical device (gastric banding) or through removal of a portion of the stomach (sleeve gastrectomy or biliopancreatic diversion with duodenal switch) or by resecting and re routing the small intestines to a small stomach pouch (gastric bypass surgery). ${ }^{2}$

The laparoscopic sleeve gastrectomy (LSG) is a mainly restrictive procedure designed to decrease appetite by reducing the ability of the stomach to distend and producing the sensation of fullness with minimal oral intake. ${ }^{3}$

Since its introduction, the indication has broadened from the first step in treatment of the super-obese to a single procedure for a wider range of patients suffering from obesity. ${ }^{4-5}$

As the sleeve gastrectomy is theoretically a more definite procedure than the band without the disadvantages of mal-absorptive bypass and the initial results reported are promising, it is necessary to report results on weight loss and co-morbidity. 6 Therefore we report our experience with LSG, evaluating the safety and efficacy of this procedure as a standalone operation.

\section{Patients and methods:}

From January 2009 to January 2012, 60 obese patients, aged 19 to 50 years, fit 
for surgery, were submitted to LSG in the department of general surgery at Zagazig University Hospital. LSG was indicated for weight reduction only for patients with a BMI $>40 \mathrm{~kg} / \mathrm{m}^{2}$ or $>35 \mathrm{~kg} / \mathrm{m}^{2}$ with severe co-morbidity related to the obesity e.g. diabetes, hypertension, hyperlipidemia, and osteoarthritis. All patients had made reasonable attempts at weight management with diet, exercise and behavior modification. The patients were informed about the aim of the study and gave their written consent.

Data collected included patient demographic data, past medical history, comorbidities, weight and BMI, operative data (operating time, blood transfusion, blood loss, complications, conversion, and drainage), duration of hospital stay and morbidity/ mortality rates. All patients were followed up in terms of weight loss and for co-morbidity improvement post-operatively at $3 \mathrm{~ms}, 6 \mathrm{~ms}$, and 1 year.

Surgical procedure: After admission all patients had preoperative evaluation including clinical examination mainly blood pressure, chest and heart examination, laboratory investigations mainly complete blood picture, plasma blood glucose levels, liver and kidney function, complete lipid profile.

Prophylactic anti-coagulant measures were done in all patients in the form of elastic stocking and subcutaneous low molecular weight heparin (Clexan 40mg) taken 6 hours before the procedure.

Positioning of the patient: After prophylactic antibiotics and general anesthesia were administered with orotracheal intubation, the patient was placed in the supine anti-Trendelenburg split-leg position, also called French position. A Foley catheter was inserted to monitor the urine output and an 18-Fr Oro-gastric tube was also inserted to decompress the stomach to have an adequate working space. Prophylactic dose of antibiotics was parentrally administered to all patients approximately 30 to 60 minutes before the procedure and another one gram was added every two hours of operation time.

Operative technique: After an established pneumo-peritoneum 5 ports were introduced into the abdominal cavity. Dissection began on the greater curvature, $6 \mathrm{~cm}$ from the pylorus, this point was usually marked by some adhesions on the dorsal side of the stomach and ventrally by small veins in a so- called crows' feet shape. The gastro-colic ligament along the greater curvature of the stomach was opened using an impedance coagulator (Ultra-sonic dissector) Harmonic scalpel and was freed as far as the cardio-esophageal junction at the root of the left pillar of the hiatus. The short gastric vessels close to the spleen were carefully coagulated separately. Guided by a 34-Fr tube illuminated tip by small lamp manually inserted in the bougie till its tip with a wire connected to a battery, guiding us to the proper site of the bougie, a laparoscopic linear stapler (Endo GIA) was introduced into the peritoneal cavity and was positioned so that it divided the stomach parallel to the orogastric tube along the lesser curvature. The instrument was fired, reloaded, and the maneuver was repeated; 1 sequential 4.8/60-mm green cartridge was used to staple the antrum followed by 3 or 4 sequential $4.2 / 60-\mathrm{mm}$ gold cartridges, to staple the remaining gastric corpusand fundus and followed by $3.5 / 60 \mathrm{~mm}$ blue cartilage $1-2 \mathrm{~cm}$ below the osephago-gastric junction, the diameter of the gastric tube was therefore 34 F. After 5 or 6 firings of the stapler, the greater curvature was completely detached from the stomach and retrieved through one of the $15 \mathrm{~mm}$ port site. A methylene blue test (150 $\mathrm{ml}$ of methylene blue fluid was introduced by a nasogastric tube) was performed to exclude staple-line leakage. In case of a staple line bleeding an Endo-clip was used to clip the bleeding point. The gastric suture line was not systematically reinforced except in the case of bleeding or positive methylene blue test, drain was routinely placed. Concomitant cholecystectomy was done in eight female patients due to gall stones.

Postoperative course: All patients were given intravenous fluids $35 \mathrm{ml} / \mathrm{kg}$ body weight during the first postoperative day then according to their fluid chart in the subsequent days. Naso-gastric tube was removed after one day. Early ambulation was advised on 


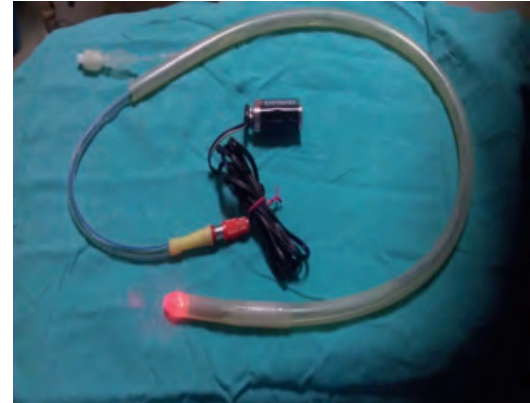

Figure (1): Illuminated bougie.

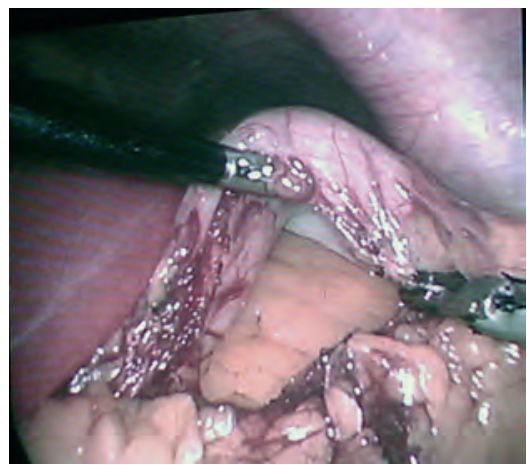

Figure (3): Division of the vascular supply using Harmonic scalpel.

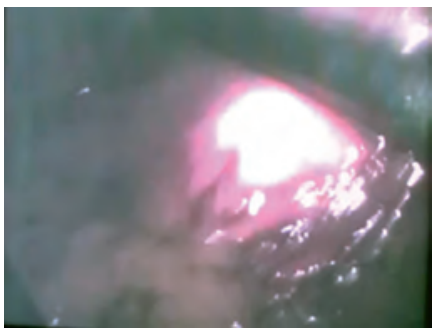

Figure (5): Illumination guided us to the proper site of bougie in the stomach.

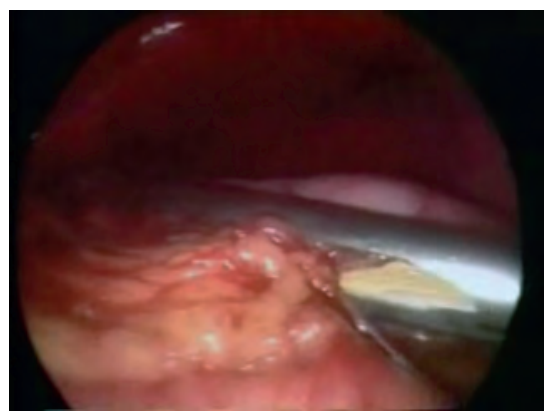

Figure (7): Sequential liner stapler using golden cartilage.

first postoperative day. Drain was removed on $3^{\text {rd }}$ postoperative day after ensuring no leak. Proton pump inhibitors were given I.V early postoperative and continued orally for 2 months after discharge. SC low molecular

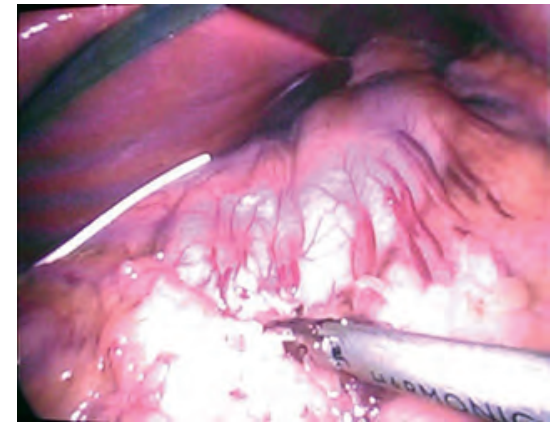

Figure (2): Dissection began on the greater curvature, $6 \mathrm{~cm}$ from the pylorus.

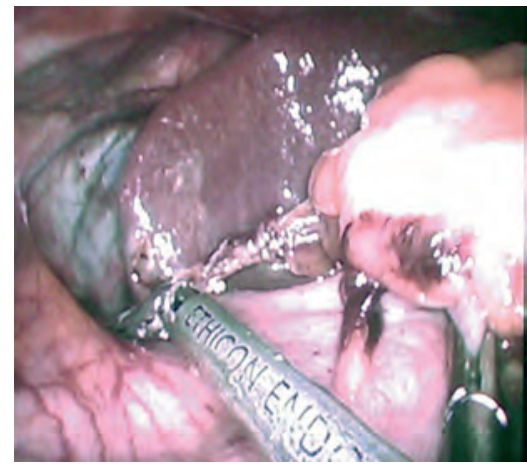

Figure (4): Division of the short gastric vessels.

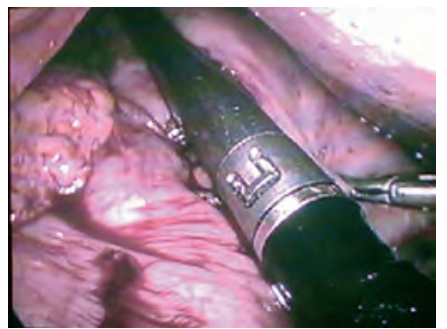

Figure (6): First Endo GIA liner stapler with green cartilage.

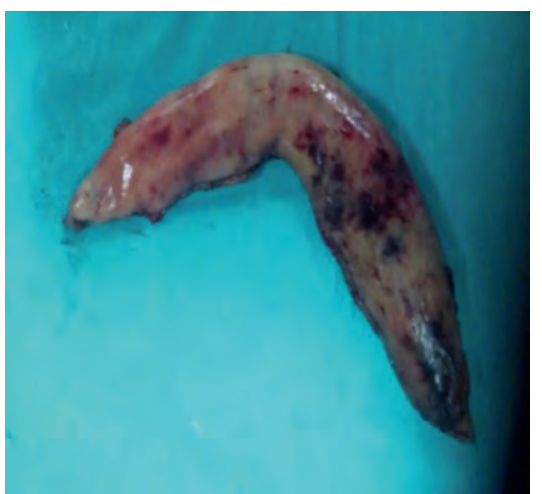

Figure (8): The resected part of the stomach.

weight heparin was continued postoperative, 6 hours after the operation (if no bleeding) by dose (clexan 40mg) every day till the patient was discharged. Drinking clear fluids was begun on the third postoperative 
Table (1): Patients preoperative characteristics of the studied cases (60 cases).

\begin{tabular}{|l|l|l|l|}
\hline & \multicolumn{1}{|c|}{ All patients } & \multicolumn{1}{|c|}{ male } & \multicolumn{1}{c|}{ female } \\
\hline Age mean \pm SD & $35 \pm 10.9$ & $23-50 \mathrm{y}$ & $19-48 \mathrm{y}$ \\
\hline Sex M/F & $15 / 45$ & 15 & 45 \\
\hline Weight (kg) & & & \\
Range & $108-195$ & $115-195$ & $108-170$ \\
Mean \pm SD & $140.2 \pm 3.2$ & $150.6 \pm 13.2$ & $130.7 \pm 3.2$ \\
\hline BMI (kg / M2) & & & \\
Range & $37.3-70.3$ & $42.3-71.3$ & $37.3-60.1$ \\
Mean \pm SD & $47.4 \pm 7.8$ & $43.15 \pm 3.3$ & $48.2 \pm 8.7$ \\
\hline
\end{tabular}

Table (2): Preoperative body mass index (BMI).

\begin{tabular}{|l|l|l|}
\hline & \multicolumn{1}{|c|}{ Range } & \multicolumn{1}{c|}{ N (\%) } \\
\hline Moderate obesity & $30-34$ & $0(0 \%)$ \\
\hline Sever obesity & $35-39$ & $16(26.6 \%)$ \\
\hline Morbid obesity & $40-49$ & $30(50 \%)$ \\
\hline Super obesity & $50-60$ & $10(16.7 \%)$ \\
\hline Super-super obesity & $>60$ & $4(6.7 \%)$ \\
\hline
\end{tabular}

Table (3): Prevalence of preoperative obesity related co-morbidities at base line.

\begin{tabular}{|l|l|l|}
\hline \multirow{2}{*}{\multicolumn{1}{|c|}{ Co-morbidities }} & \multicolumn{2}{c|}{$\begin{array}{c}\text { Patient group } \\
\text { (60) Case of morbid obesity }\end{array}$} \\
\cline { 2 - 3 } & \multicolumn{1}{|c|}{ No } & $\%$ of total patients \\
\hline Diabetes & 12 & 20 \\
\hline Hypertension & 7 & 11.6 \\
\hline Hyperlipidemia & 8 & 13.4 \\
\hline Osteoarthritis & 3 & 5 \\
\hline
\end{tabular}

Table (4): Operative data.

\begin{tabular}{|l|l|l|}
\hline & \multicolumn{1}{|c|}{ Range } & \multicolumn{1}{c|}{ Mean \pm SD } \\
\hline Early operation time (Min) & $200-240$ & $205 \pm 21.4$ \\
Late operative(Min) & $135-180$ & $150 \pm 11.5$ \\
\hline Intra-operative blood loss (cc) & $100-300$ & $129.4 \pm 10.8$ \\
\hline Post operative hospital stay (days) & $2-5$ & $3.1 \pm 0.6$ \\
\hline Conversion to open & 1 pts (1.7\%) & \\
\hline Concomitant chlecystectomy & 8 pts (13.3\%) & \\
\hline
\end{tabular}

day. The patients were discharged 2-5 days postoperative according to postoperative course.

Follow up three and six month's postoperative visit: Body weight, BMI and percentage of excess weight loss (\%EWL). Excess weight was calculated as the patient's current weight minus his or her ideal body weight, and the \%EWL is the ratio of weight lost at each time point over the total excess weight. Complete blood picture, fasting blood glucose, serum creatinine and complete lipid profile. One year postoperative visit: Body weight, percentageof excess weight loss 
Table 5: Early intraoperative and postoperative complications 5 patients (8.3\%).

\begin{tabular}{|l|l|l|}
\hline & NO. of Pts & \multicolumn{1}{|c|}{$\%$} \\
\hline Early intra-operative complications: & & \\
Organ injury & 0 & 0 \\
Bowel ischaemia & 0 & 0 \\
Bleeding & 1 & 1.7 \\
\hline Early postoperative complications: & & \\
Bleeding & 1 & 1.7 \\
Gastric leak & 0 & 0 \\
Paralytic ileus & 2 & 3.4 \\
Wound infection & 1 & 1.7 \\
\hline Re-operation & 2 & 3.4 \\
\hline
\end{tabular}

Table (6): Changes of weight and BMI among the studied group before and after operation.

\begin{tabular}{|c|c|c|c|c|c|c|}
\hline & \multicolumn{4}{|c|}{ Changes of weight, BMI, \%EWL } & \multirow{2}{*}{$\begin{array}{c}\text { One way } \\
\text { ANOVA } \\
\text { (Fstatistic) }\end{array}$} & \multirow[b]{2}{*}{ P-value } \\
\hline & Before & $\begin{array}{l}3 \text { months } \\
\text { after }\end{array}$ & $\begin{array}{l}6 \text { months } \\
\text { after }\end{array}$ & $\begin{array}{l}1 \text { year } \\
\text { after }\end{array}$ & & \\
\hline $\begin{array}{l}\text { Weight (kg) } \\
\text { mean } \pm \text { SD }\end{array}$ & $140 \pm 3.2$ & $120.7 \pm 1.32$ & $100.6 \pm 3.2$ & $90.3 \pm 1.1$ & $70.8 * *$ & $<0.001$ \\
\hline $\begin{array}{l}\text { BMI }(\mathrm{kg} / \mathrm{m} 2) \\
\text { mean } \pm(\mathrm{SD})\end{array}$ & $47.4 \pm 7.8$ & $43.71 \pm 6.21$ & $33.08 \pm 5.3$ & $30.5 \pm 2.93$ & $31.97 * *$ & $<0.001$ \\
\hline$\%$ Of EWL & & $30 \pm 12$ & $40.5 \pm 13$ & $48.7 \pm 15$ & & $<0.001$ \\
\hline
\end{tabular}

Table (7): Prevalence of co-morbidities related to morbid obesity before and after surgery.

\begin{tabular}{|c|c|c|c|c|c|c|c|c|c|}
\hline \multirow{3}{*}{ Co-morbidities } & \multicolumn{8}{|c|}{ Patient Group( 30 cases) } & \multirow{3}{*}{ P-value } \\
\hline & \multicolumn{2}{|r|}{ Before } & \multicolumn{2}{|r|}{ After } & \multicolumn{2}{|c|}{$\begin{array}{l}\text { Resolution } \\
\text { completely }\end{array}$} & \multicolumn{2}{|c|}{$\begin{array}{c}\text { Significant } \\
\text { improvement }\end{array}$} & \\
\hline & $\mathrm{N}$ & $\%$ of total & $\mathrm{N}$ & $\%$ of total & $\mathrm{N}$ & \%of total & $\mathrm{N}$ & $\%$ of total & \\
\hline Diabetes & 12 & 40 & 2 & 16.7 & 8 & 66.6 & 2 & 16.7 & $<0.05$ \\
\hline Hypertension & 7 & 23.3 & 2 & 28.6 & 4 & 57.1 & 1 & 14.3 & $<0.05$ \\
\hline Hyperlipidemia & 8 & 26.7 & 0 & 0 & 8 & 100 & & & $<0.001$ \\
\hline osteoarthritis & 3 & 10 & 0 & 0 & 3 & 100 & & & $<0.001$ \\
\hline
\end{tabular}

(\%EWL), and BMI, complete blood picture, fasting blood glucose, serum creatinine and complete lipid profile.

Statistical analysis: The data were collected presented and analyzed using SPSS-PC (version 10) software. Comparisons between measures (Mean $\pm \mathrm{SD}$ ) were done using paired t-test for two paired groups; also, qualitative categories were expressed in the form of frequency and percentage. The test results were considered significant when $P$. value was $<0.05$.

\section{Results:}

Sixty patients were included in the study; 45 females (85\%) and 15 males (15\%). Their ages ranged from 19 to 50 years with a mean age of $35 \pm 10.9$ years. Preoperatively the weights of our patients ranged $108 \mathrm{~kg}$ to 195 $\mathrm{kg}$ with a mean weight of $140.2 \pm 3.2 \mathrm{~kg}$. BMI ranged from 37.3 to $70.3 \mathrm{~kg} / \mathrm{m}^{2}$ with a mean BMI of $47.4 \pm 7.8 \mathrm{~kg} / \mathrm{m}^{2}$ Table $(\mathbf{1 , 2})$.

In our study, 30 patients (50\%) had comorbidities. 12 patient were diabetic, 7 patients had hypertension, 8 patients had hyperlipidemia and 3 had osteoarthritis 
Table (3).

In our study sleeve gastrectomy was done by laparoscopy in 59 patients (98.3\%) with conversion to open surgery in one case (1.7\%). The intra-operative blood loss ranged from (100 cc to $300 \mathrm{cc}$ ) with a mean blood loss of $(129.4 \pm 10.8 \mathrm{cc})$. The operation time ranged from (200 to 240 minutes) in early cases and (135 to180 $\mathrm{min}$ ) in the late cases, with a mean operation time of $(155 \pm 18.5$ min). Postoperative hospital stay ranged from (2 to 5 days) with a mean hospital stay of (3.1 \pm 0.6 days) Table (4). The incidence of early intra-operative complication included one case $(1.7 \%)$ of uncontrolled bleeding from the site of short gastric vessels that was explored for its management. Laparoscopic cholecystectomy was done in eight female patients (13.3\%) who suffered from gall stones.

In our study no mortality and the rate of early postoperative complications was $6.7 \%$ in 4 patients, 1 with postoperative bleeding who needed exploration, 1 with wound infection (in the patient explored for bleeding) and two with paralytic ileus. We didn't report other complications as gastric leak, organ injury, bowel ischaemia, marginal ulcer, and dumping syndrome.

In our study, two patients needed exploration , one of them was female patient 48 years old with intra-operative bleeding during dissection and division of short gastric vessels who needed conversion to open sleeve gastrectomy and the other one was also female patient 21 years old who presented at night of the day of the operation with hypotension and abdominal rigidity, the patient was treated conservatively with intravenous fluid and blood transfusion without improvement so she was explored at the morning of day 1 postoperative by left sub-costal incision, hemoperitoneum with bleeding from the site of the short gastric and subphernic hematoma was found. Reinforcement of the stapled line with polyprolene to avoid leak with traction of the stomach during the exploration, evacuation of the hematoma, ligation of the bleeding vessels at the area of short gastric were done and with closure with tube drain.
The patient was discharged at the day 5 postoperative. In our study, blood transfusion was needed in two patients who needed exploration, about 3 units of packed RBCs to each one. Table (5).

There was a highly statistical significant difference between mean scores of weight and BMI before surgery and (three, six and twelve) months after surgery. The mean pre operative weight was $140 \pm 3.2 \mathrm{~kg}$ and one year after operation it was reported to be 90 . $3 \pm 1.1 \mathrm{~kg}$ with a mean reduction in weight of $50 \mathrm{~kg}$ which was statistically significant (P-value $<0.001$ ) the mean pre operative BMI was $47.4 \mathrm{~kg} / \mathrm{m}^{2}$ and. One year after operation it was reported to be $30.5 \mathrm{~kg} / \mathrm{m}^{2}$ with a mean reduction in BMI of $17 \pm 4.9 \mathrm{~kg} / \mathrm{m}^{2}$ which were statistically significant $(\mathrm{P}$-value $<0.001$ ) and the mean percentage of excess weight loss was $48.7 \% \pm 15$ at one year Table (6).

In our study we had significant reduction in the prevalence of hyperslipidemia, and diabetes disease One year after surgery there was a highly statistical significant difference in the reduction of fasting plasma glucose levels after surgery among those with diabetes mellitus. While in those without diabetes mellitus, the reduction was not significant. We had also significant reduction in the prevalence of osteoarthritis Table (7).

We had observed that 26 (86.7\%) cases of patients with co-morbidities had shown complete resolution (76.7\%) in 23 cases and improvement of the disease in 3 cases $(10 \%)$ with only 4 cases (13.3\%) continued the same treatment. In diabetic patients 8 cases discontinued the treatment, 2 cases reduced the doses of the drugs and 2 cases continued the same treatment. In hypertensive patients 4 cases discontinued the treatment, 1 case reduced the doses of the drugs and 2 cases continued the same treatment. All cases of hyperlipidemia and osteoarthritis discontinued the treatment.

\section{Discussion:}

Bariatric or weight loss surgery is the only treatment for morbid obesity that confers definitive weight loss at long-term followup. In addition to weight reduction there is a 
strong possibility of amelioration or even cure of various co-morbid conditions associated with obesity. ${ }^{7}$

LSG is an innovative procedure for the management of obesity. It was originally developed as a first-stage bariatric procedure to reduce surgical risk in high-risk patients through the induction of dramatic weight loss. Analysis of the literature suggests LSG is efficacious in the short term and may offer certain advantages when compared to the existing options of LAGB and LRYGB. These advantages include: technical efficiency, lack of an intestinal anastomosis, normal intestinal absorption, no risk of internal hernias, no implantation of a foreign body, pylorus preservation (prevents dumping syndrome), the risk of peptic ulcer is low; and the absorption of nutrients, vitamins, minerals, and drugs is not altered, and finally LSG may be considered the most appropriate option in extremely obese patients. ${ }^{8}$ Moreover, the entire upper gastrointestinal tract remains accessible for endoscopic assessment. ${ }^{9}$ LAGB is not associated with a decline of the circulating levels of ghrelin, ${ }^{10}$ and Karamanakos et $\mathrm{al}^{11}$ showed a higher ghrelin level reduction after LSG than after LGB in a prospective, double-blind study. Concerns remain however, regarding the risks and important major complications associated with LSG including staple line leak (1.17\%), post-operative hemorrhage (3.57\%), and the irreversibility of LSG. ${ }^{12}$

It has been suggested that the size of the gastric tube is a factor influencing the degree of weight loss. This may be partly explained by complete resection of the gastric fundus, which contains most of the ghrelin-producing cells. ${ }^{13,14}$ No consensus, however, has been reached regarding the optimal dilator size that should be used to create the lesser curve conduit, with various reports recommending diameters between 32 and $60 \mathrm{~F}$. The antrum has been spared in some papers and removed in others. ${ }^{15}$ In our study we had spared the antrum.

Undoubtedly some surgeons are stapling flush with the bougie at the oesophagogastric junction whilst others are leaving a larger cuff of tissue. Here, we left a 1-2 cm cuff of tissue at the oesophagogastric to reduce the leak rate in a region which has potential weakness due to the decussation of esophageal musculature radially over the proximal stomach. ${ }^{15}$

Rosenthal (2011) ${ }^{16}$ reported that; the mean patient age was 42 years, with $26 \%$ male and $73 \%$ female. The mean BMI of the patients was $44 \pm 4.7 \mathrm{~kg} / \mathrm{m}^{2}$. The mean bougie size was $37 \mathrm{~F} \pm 5.92 \mathrm{~F}$. The average length of hospital stay was $3.1 \pm 0.93$ days. The conversion rate was $1.05 \pm 1.85 \%$. On average, patients experienced a $1.06 \%$ leak rate and $0.35 \%$ stricture rate.

Our study was done on sixty patients; the mean patient age was $35 \pm 10.9$ years, with $15 \%$ male and $75 \%$ female. The mean weight of our patients was $140.2 \pm 3.2 \mathrm{~kg}$ and the mean BMI of $47.4 \pm 7.8 \mathrm{~kg} / \mathrm{m}^{2}$. LSG was done by laparoscopy in 59 patients (98.3\%) with conversion to open surgery in one case (1.7\%). Concomitant cholecystectomy was done in 8 female patients, and the mean operative time was $155 \pm 18.5 \mathrm{~min}$. The average length of hospital stay was $3.1 \pm 0.6$ days. All cases in our study were performed with a 34F bougie with preservation of the last $5 \mathrm{~cm}$ of the antrum and a small cuff of gastric tissue of less than $2 \mathrm{~cm}$ in size at the oesophagogastric junction.

In our study, no mortality occurred and the rate of early postoperative complications was $6.7 \%$ in 4 patients. We reported no gastric leak or organ injury possibly due to certain intraoperative maneuvers; a running fat retraction stitch was easy and quick to perform and provided optimum visualization, particularly for the last crucial firings of the stapler at the fundus. When using the harmonic scalpel it was helpful to 'rest' between burns and cool the blade on surrounding omental fat to prevent gastric, splenic or pancreatic injury. ${ }^{17}$

In our series two cases had been opened, one during the operation due to uncontrolled bleeding from the short gastric vessels and the other one due to bleeding also who presented with shock at the night of operation and was explored with left subcostal incision. These two patients only needed blood transfusion in the form of 3 units of packed RBCs for each 
of them.

The effect of LSG on weight loss was significant in our study, the mean weight reduction was $50 \mathrm{~kg}$ after one year, the mean reduction in BMI was $17 \mathrm{~kg} / \mathrm{m}^{2}$ after one year and the mean percentage of excess weight loss (\%EWL) was $40.5 \%$ and $48.7 \%$ at 6 months and one year respectively.

In a study conducted by Cottam $\mathrm{D}$ et al ${ }^{8}$ involving 126 patients with a preoperative mean BMI value of $65.3 \pm 0.8$, the mean $\%$ EWL after LSG at one year was $46 \%$. One distant mortality was encountered, and the incidence of major complications reached $13 \%$. Rosenthal RJ et al ${ }^{18}$ reported 30 patients with a mean preoperative BMI value of 41.4. Mean weight loss in this study at three and six months postoperatively was $22.7 \mathrm{~kg}$ and $30.5 \mathrm{~kg}$ and mean \% EWL 40.7 and 52.8, respectively.

The degree of weight loss in our series was similar to that reported by Mognoletal ${ }^{19}$ (EWL of $41 \%$ at 6 months) who used the same size of gastric tube (34 F), but it was lower than the results reported by Himpenset al. ${ }^{5}$

The other important endpoint was reduction of medicaments necessary for an obesity related chronic condition. The influence on co-morbidity is the most important endpoint in bariatric studies. Vidal et $\mathrm{al}^{20}$. reported the diabetes and metabolic syndrome reduction in severely obese patients. They reported a comparable effectiveness for this specific group for sleeve gastrectomy as well as gastric by-pass. In the study of De Paula ${ }^{21}$ promising results were reported for the laparoscopic interposition of an ileum segment in to the proximal jejunum. In one study thirty patients with diabetes were treated by LSG and there was a resolution of $63 \%$ at 6 months followup. ${ }^{22}$ In our study the resolution rate for osteoarthritis and hyperlipidemia was 100\% after 3 months. The resolution rate of diabetes was $66.6 \%$ and improvement in $16.7 \%$ of total cases of diabetes. The resolution rate of hypertension was $57.1 \%$ and improvement was $14.3 \%$ of total cases of hypertension.

Conclusion, sleeve gastrectomy can be performed safely with acceptable complication rates and good weight loss. The percentage excess weight loss reported from this series of up to $48 \%$ at one year is encouraging with improvement of the main co-morbid diseases. Debates will continue as to what is the optimal bariatric procedure.

\section{Reference:}

1- Frezza EE: Laparoscopic vertical sleeve gastrectomy form or bid obesity. The future procedure of choice? Surg Today 2007; 37: 275-281.

2- Almogy G, Crooks PF, Anthone GJ: Longitudinal gastrectomy as a treatment for the high-risk super-obese patient. Obes Surg 2004; 14: 492-497.

3- Lee CM, Feng JJ, Cirangle PT, Jossart GH: Laparoscopic vertical sleeve gastrectomy form or bid obesity in 216 patients: Report of two-year results (abstr.). Surg Endosc 2006; 20 (Suppl.): 255.

4- Aggarwal S, Kini SU, Herron DM: Laparoscopic sleeve gastrectomy form or bid obesity: A review. SOARD 2007; 3: 189-194.

5- Himpens J, Dapri G, Cadiere GB: A prospective randomized study between laparoscopic gastric banding and laparoscopic isolated sleeve gastrectomy: Results after 1 and 3 years. Obes Surg 2006; 16: 1450-1456.

6- Nienhuijs SW, de Zoete JP, Berende CAS, et al: Evaluation of laparoscopic sleeve gastrectomy on weight loss and co-morbidity. International Journal of Surgery 2010; 8: 302-304.

7- Khwajaa HA, Bonanomib G: Bariatric surgery: Techniques, outcomes and complications. Current Anaesthesia \& Critical Care 2010; 21: 31-38.

8- Cottam D, Qureshi FG, Mattar SG, et al: Laparoscopic sleeve gastrectomy as an initial weight-loss procedure for high-risk patients with morbid obesity. Surg Endosc 2006; 20(6): 859-863.

9- Foschi D, Corsi F, Rizzi A,Asti E, Carsenzuola V, Vago T, et al: Vertical banded gastroplasty modifies plasma ghrelin secretion in obese patients. Obes Surg 2005; 15: 1129-1132.

10- Iannelli A, Facchiano E, Gugenheim J: Internal hernia after laparoscopic Roux-en-Y gastric bypass for morbid obesity. Obes Surg 2006; 16: 1265-1271.

11- Karamanakos SN, Vagenas K, Kalfarentzos F, Alexandrides TK: Weight loss, appetite suppression, and changes in fasting and postprandial ghrelin and peptide-YY levels 
after Roux-en-Y gastric bypass and sleeve gastrectomy: A prospective, double blind study. Ann Surg 2008; 247: 401-407.

12- Shi X, Karmali S, Arya M, et al: A review of laparoscopic sleeve gastrectomy for morbid obesity. Obes Surg 2010; DOI 10.1007/ s11695-010-0145-8.

13- Langer FB, Reza Hoda MA, Bohdjalian A, Felberbauer FX, Zacherl J, Wenzl E, et al: Sleeve gastrectomy and gastric banding: Effects on plasma ghrelin levels. Obes Surg 2005; 15: 1024-1029.

14- Ariyasu H, Takaya K, Tagami T, et al: Stomach is a major source of circulating ghrelin, and feeding state determines plasma ghrelin-like immunoreactivity levels in humans. J Clin Endocrinol Metab 2001; 86: 4753-4758.

15- David Fuks, MD, Pierre Verhaeghe, MD, Olivier Brehant, MD, et al: Results of laparoscopic sleeve gastrectomy: A prospective study in 135 patients with morbid obesity. J Surg 2009; 145: 106-113.

16- Rosenthal RJ: International sleeve gastrectomy expert panel consensus statement: Best practice guidelines based on experience of $>12.000$ cases. Surgery for Obesity and related Disease 2011; 27: 1-12.
17- Armstrong J, O’Malley SP: Outcomes of sleeve gastrectomy for morbid obesity: A safe and effective procedure. Int J Surg 2010; 8: 69-71.

18- Roa PE, Kaidar-Person O, Rosenthal RJ, et al: Laparoscopic sleeve gastrectomy astreatment for morbid obesity: Technique and short-term outcome. Obes Surg 2006; 16: 1323-1326.

19- Mognol P, Chosidow D, Marmuse JP: Laparoscopic sleeve gastrectomy as an initial bariatric operation for high-risk patients: Initial results in 10 patients. Obes Surg 2005; 15: 1030-1033.

20- Vidal J, Ibarzabal A, Romero F, et al: Type 2 diabetes mellitus and the metabolic syndrome following sleeve gastrectomy in severely obese subjects. Obes Surg 2008; 18(9): 1077-1082.

21- De Paula AL, Macedo AL, Rassi N, et al: Laparoscopic treatment of metabolic syndrome in patients with type 2 diabetes mellitus. Surg Endosc 2008; 22(12): 2670-2678.

22- Rosenthal R, Li X, Samuel S, et al: Effect of sleeve gastrectomy on patients with diabetes mellitus. Surg Obes Relat Dis 2008; 18 [Epub ahead of print]. 